\title{
One stage repair for an oesophageal fistula after pneumonectomy using an omental pedicle flap
}

\author{
MINEO ASAOKA, MUNEHISA IMAIZUMI, MASAFUMI KAJITA, TATSUO UCHIDA, \\ TAKAO NIIMI, TOSHIO ABE
}

From the Department of Thoracic Surgery, Nagoya University School of Medicine, Nagoya, Japan

\begin{abstract}
A 67 year old man developed an oesophageal fistula after a pneumonectomy that was complicated by an empyema. An omental pedicle flap was brought through the diaphragm to repair the fistula and to fill the empyema space. The outcome was successful.
\end{abstract}

An oesophageal fistula is a rare but serious complication of pneumonectomy. Almost all reports recommend operative intervention, including closure of the fistula; its reinforcement with a pleural or pedicle muscle flap; and obliteration of the empyema cavity. We have used an omental pedicle flap for treatment of the fistula.

\section{Case report}

A 67 year old man with squamous cell carcinoma of the lung had a left pneumonectomy in December 1986. An empyema developed on the 13th postoperative day. After culture of the pleural fluid, which grew Staphylococcus aureus, Klebsiella oxytoca, and Serratia marcescens, pleural lavage and instillation of appropriate antibiotics were started. After food debris was noted in the drained liquid on the 25 th postoperative day an oesophageal fistula was confirmed by oesophagography (figure) and oesophagoscopy. Oral intake was stopped and nasoduodenal feeding using a DUO tube (Argyle) was instituted. Closed drainage, lavage of the empyema space, and oesophagoscopic application of fibrin glue all failed to close the fistula.

In April 1987 direct closure was attempted. The suture line was reinforced with an omental pedicle flap that also filled the empyema space. Recovery was uneventful and the patient has been well for 10 months.

Surgical technique The patient was placed in the decubitus position with the hips more or less horizontal. A posterolateral thoracotomy disclosed the empyema cavity, which was curetted and washed thoroughly. The peel around the oesophageal fistula was dissected carefully, and the fistula closed with 3-0 Vicryl in one layer.

Laparotomy was then performed by a subcostal approach. The omentum was freed by dissection of the right gastro-

Address for reprint requests: Dr $M$ Imaizumi, Department of Thoracic Surgery, Nagoya University School of Medicine, 65 Tsurumai, Showa-ku, Nagoya City, Aichi Prefecture, Japan 466.

Accepted 20 May 1988 epiploic artery, with preservation of the left gastroepiploic artery and the communications of the two arteries. This omental pedicle flap was brought through a $3 \mathrm{~cm}$ incision in the anterior part of the hemidiaphragm, to which it was fixed; it was then used to reinforce the suture line that closed the fistula and to fill the empyema cavity. A tube jejunostomy was made for postoperative feeding and chest and abdominal drains were left in situ.

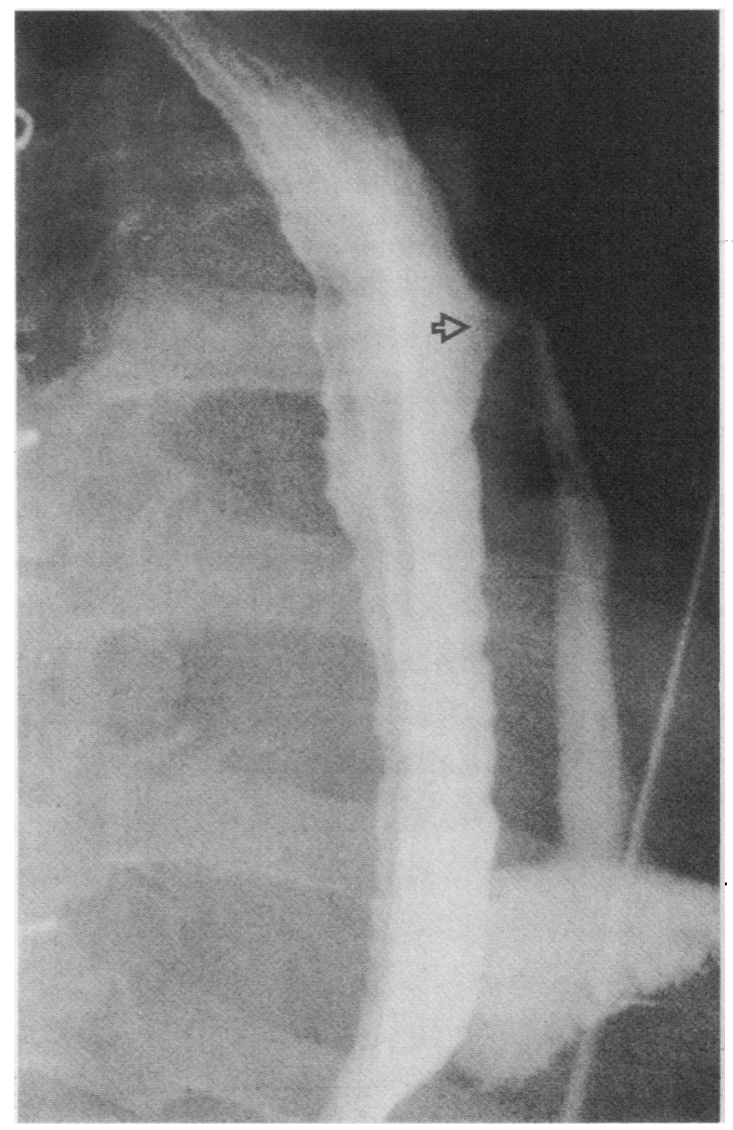

Oesophagogram showing the oesophageal fistula communicating with the left pleural cavity (arrow). 


\section{Discussion}

An oesophageal fistula presenting early in the postoperative period is likely to be the result of surgical trauma, or of oesophageal ischaemia due to extensive dissection. A late fistula is due to the development of a bronchopleural fistula and abscess, or invasion by residual tumour.'

Although the incidence of postpneumonectomy oesophageal fistula is about $0.5 \%$ according to Evans ${ }^{2}$ and Shama, ${ }^{3}$ it may well be higher in extended lung cancer operations. Adkins ${ }^{4}$ asserted the importance of limiting surgical trauma and recommended careful dissection and the use of a nasogastric tube to help to identify the oesophagus.

The treatment for an oesophageal fistula consists of the control of infection, the nourishment of the patient, direct closure of the fistula, reinforcement of the suture line with a pedicle flap, and obliteration of the empyema space. Nutrition for the exhausted, emaciated patient should be by intravenous hyperalimentation or tube feeding. When the emphyema space has been decompressed and the patient is in optimal condition, the procedure of choice is direct closure and reinforcement of the suture line, which in the past has been done with a pleural ${ }^{5}$ or intercostal muscle flap. ${ }^{6}$ The empyema cavity may also be obliterated by means of an intercostal or pectoralis muscle flap, ${ }^{7}$ or thoracoplasty according to some authors. ${ }^{26}$

The omental pedicle flap described here fulfils two functions, reinforcing the suture line and filling the empyema cavity. Omentum is appropriate for filling the postpneumonectomy empyema cavity because it is bulky and rich in blood and lymphatic flow, and has the potential to prevent infection and to minimise the deformity of the chest. It has already been found useful in the management of bronchopleural fistulas. $^{8}$
The procedure we describe has some disadvantages; it mas? be difficult to free the omentum if the patient has hat abdominal surgery, infection might spread into the peritoneal cavity, and an internal hernia or adhesive ileus iक possible. Although the postoperative course of this patien has fortunately been uneventful, the procedure should be undertaken only for postpneumonectomy empyema.

\section{References}

1 Takaro T, Walcup HE, Okano T. Esophagopleural fistula as at complication of thoracic surgery. J Thorac Cardiovasc Surg 1960;40:179-93.

2 Evans JP. Postpneumonectomy oesophageal fistula. Thoraxio 1972;27:674-7.

3 Shama DM, Odell JA. Esophagopleural fistula after pneumo-O nectomy for inflammatory disease. $J$ Thorac Cardiovasc Surg 1985;89:77-81.

4 Adkins PC, Aaron BL. Complication of pulmonary resection. In:Z Hardy JD, ed. Complications in surgery and their management. Philadelphia: Saunders, 1981:313-29.

5 Benjamin I, Olsen AM, Ellis FH Jr. Esophagopleural fistula: a rare postpneumonectomy complication. Ann Thorac Surg트 1969;7:139-44.

6 Engelman RM, Spencer FC, Berg P. Postpneumonectomy $\vec{\varrho}$ esophageal fistula: successful one-stage repair. J Thorac $\infty$ Cardiovasc Surg 1970;59:871-6.

7 Mud HJ, van Houten H, Slingerland R, Sonneveld P, Kho S. AO modified pectoralis muscle flap for closure of postpneumonectomy esophagopleural fistula; Technique and result. $A n n \bar{\square}$ Thorac Surg 1987;43:359-62.

8 Virkkula L, Eerola S. Use of omental pedicle for treatment of bronchial fistula after lower lobectomy. Scand J Thorac 0 Cardiovasc Surg 1975;9:287-90. 